\title{
Efficacy of Drugs Used in Gastro-Oesophageal Reflux: Network Meta-Analysis*
}

\author{
Rafael Bolaños-Díaz ${ }^{1}$, Héctor Velarde-Criado ${ }^{2}$, Erik Cóndor-Mori ${ }^{3}$ \\ ${ }^{1}$ Unidad de Análisis y Generación de Evidencias en Salud Pública (UNAGESP), Instituto Nacional de Salud (INS), Lima, Perú; \\ ${ }^{2}$ Departamento de Gastroenterología, Hospital Central de Aeronáutica, Lima, Perú; ${ }^{3}$ Unidad de Epidemiología Clínica, Universidad \\ Peruana Cayetano Heredia, Lima, Perú. \\ Email: rbolanosd@yahoo.es, rbolanos@ins.gob.pe,rbolanosd@unmsm.edu.pe
}

Received January $15^{\text {th }}, 2013$; revised February $18^{\text {th }}, 2013$; accepted April $2^{\text {nd }}, 2013$

Copyright (C) 2013 Rafael Bolaños-Díaz et al. This is an open access article distributed under the Creative Commons Attribution License, which permits unrestricted use, distribution, and reproduction in any medium, provided the original work is properly cited.

\begin{abstract}
Introduction: It is important to rank the clinical efficacy of different anti-reflux agents to promote their rational use. Objective: To combine the results of randomized clinical trials that have compared the incidence of symptoms related to gastro-oesophageal reflux (GER) with/without endoscopic evidence of oesophagitis in a network meta-analysis and thus rank the main anti-reflux therapies according to the magnitude of their clinical efficacy. Method: Inclusion criteria: 1) randomized controlled trials that compare anti-reflux agents (alginates (ALG), proton-pump inhibitors (PPI), $\mathrm{H}_{2}$ histamine receptor antagonists $\left(\mathrm{H}_{2} \mathrm{RA}\right)$, antacids $(\mathrm{AA})$, gastrokinetics $(\mathrm{GK})$ ) in open designs as compared to placebo or in comparative designs (head-to-head); 2) outcome of interest measured in some scale representing the significant improvement of reflux symptoms; 3) GER diagnosis with/without oesophagitis endoscopic evidence. We collected available clinical trials for each one of the direct comparisons. The Odds Ratio (OR) was used additionally to calculating lnOR and its Standard Error (SE[lnOR]) to measure effects in a network meta-analysis. Results: Network meta-analysis has placebo as a reference intervention. Initial treatments with PPI or ALG are the two interventions that significantly differ from the others: $\mathrm{H}_{2} \mathrm{RA}$, AA and GK. At the same time, the latter are significantly different from the placebo. In contrast to placebo, ORs for ALG, PPI, $\mathrm{H}_{2} \mathrm{RA}$, AA and GK were 4.72 (95\% CI: 3.39, 6.57), 4.00 (95\% CI: 3.30, 4.85), 1.73 (95\% CI: 1.54, 1.95), 1.41 (95\% CI: 1.12, 1.76), and 1.86 (95\% CI: 1.32, 2.63), respectively. Conclusion: ALG or PPI seem to be the two most effective alternatives in short-time management of GER with or without oesophagitis.
\end{abstract}

Keywords: Gastro-Oesophageal Reflux; Network; Meta-Analysis

\section{Introduction}

Epigastric or retrosternal heartburn (pyrosis) is one of the most reported conditions and is the primary symptom of gastro-oesophageal reflux (GER). Reflux occurs more frequently after eating and the relationship between the consumption of some food and pyrosis (acid reflux generating food) is well known. Besides, many people experience pyrosis when lying on their back. Hence, troubles are more evident during sleep hours. Thus, propping up the patient's head to reduce GER became a standard medical recommendation for every patient who suffered from this condition together with the use of medication that neutralizes or reduces gastric acidity. However, the truth is that most of the people who suffer from acid reflux and pyrosis practice self-medication and only when

\footnotetext{
${ }^{*}$ This study has been entirely funded by the authors.
}

the situation becomes persistent or chronic do they look for professional aid.

There is currently a large variety of over-the-counter (OTC) products worldwide for symptomatic treatment of acid reflux and dyspepsia. These include numerous antacid agents (AA), alginate/antacid (ALG) formulations, $\mathrm{H}_{2}$ histamine receptor antagonists $\left(\mathrm{H}_{2} \mathrm{RA}\right)$ and proton pump inhibitors (PPIs). Recently, due to the significant efficacy of the latter agent, they are frequently used as a first-line intervention. Nevertheless, their use is not exempted from adverse effects such as rebound hyperacidity and malabsorption, opportunistic intestinal infections (C. difficile), or significant interactions with magnesium [1-4], due to which it is often preferable to reserve this kind of agents for more defined clinical conditions that require their rational use.

Although formulations based on ALG are often classi- 
fied as antacids, these are really different agents. As compared to traditional antacids, which chemically neutralize gastric acid or $\mathrm{H}_{2} \mathrm{RA} / \mathrm{PPIs}$ which reduce acid secretion, products with ALG seem to act locally and with no evidence of systemic effects $[5,6]$. However, to optimize such local effect these formulations need to be associated with some antacid to allow for the formation of a viscous gel and for its floatability. The use of ALGs is well disseminated in managing GER and their efficacy data were recently evaluated in a meta-analysis. Nevertheless, in most studies on effectiveness aspects and anti-reflux therapy cost-effectiveness, the focus has been most exclusively in the use of PPI and $\mathrm{H}_{2}$ RA [7-12].

The aim of the study is to combine the results of randomized clinical trials that have compared the incidence of symptoms related to GER (with/without oesophagitis endoscopic evidence) in a network meta-analysis and thus rank the main anti-reflux therapies according to the magnitude of their clinical effectiveness.

\section{Material and Methods}

The literature search was based upon the following research question: Which are the most effective agents in treating GER?

Research question components depended on the PICO methodology as follows: POPULATION: adult patients with symptoms related to GER, with/without endoscopic evidence of oesophagitis; INTERVENTION: anti-reflux agents; COMPARISON: Placebo; OUTCOME: Significant symptom relief rate.

The search was only in literature in English. We used the following terms:

("alginic acid" [ti] OR "alginate" [ti] OR "antacid" [ti] OR "Histamine Receptor Antagonist" [ti] OR "ranitidine" [nm] OR "famotidine" [nm] OR "nizatidine" [nm] OR "cimetidine" [nm] OR "Proton Pump Inhibitors" [ti] OR "omeprazole" [nm] OR "lansoprazole" [nm] OR "rabeprazole" [nm] OR "pantoprazole" [nm]) AND ("heartburn" [All Fields] OR "gastro-(o)esophageal reflux disease" [ti] OR "gastro-oesophageal reflux disease" [All Fields] OR "GER" [All Fields] OR "GORD" [All Fields]) AND "endoscopy negative" [tw] AND ("humans" [MeSH Terms] AND (Meta-Analysis [ptyp] OR Randomized Controlled Trial [ptyp]) AND (English [lang]) AND "adult" [MeSH Terms]).

The following were the databases we used: PUBMED, COCHRANE library, EMBASE and MEDLINE (until July, 2012). We carefully checked the reference lists of found articles to complete our tracking. Unpublished studies were not considered.

Two researchers reviewed studies published in the above mentioned databases. Unpublished studies were not tracked. The search was limited to controlled clinical trials or meta-analyses performed on adult individuals ( $>18$ years).

The following inclusion criteria were applied: 1) randomized controlled trials that compare anti-reflux agents (alginates (ALG), proton-pump inhibitors (PPI), $\mathrm{H}_{2}$ histamine receptor antagonists $\left(\mathrm{H}_{2} \mathrm{RA}\right)$, antacids (AA), gastrokinetics (GK)) in open designs as compared to placebo or in comparative designs (head-to-head); 2) outcome of interest measured in some scale representing the significant improvement of reflux symptoms; 3) GER diagnosis with/without endoscopic evidence of oesophagitis. We collected available clinical trials for each one of the direct comparisons. Likewise, the following exclusion criteria were considered: 1) high doses of anti-reflux agents; 2) no measurement of clinical improvement; 3) duplication of a published article.

Finally, manual searches were done in every reference list of initially selected publications. Besides, we contacted some domestic and international experts to request a complementary literature search from them and to inquire about their knowledge of additional studies besides those our team had already found. We applied the Jadad scale to value the quality of selected studies [13].

\section{Data Analysis}

A network can be drafted by considering that there are multiple comparisons among different agents used for GER, making a difference between direct and indirect comparisons. We collected available clinical trials for each one of the direct comparisons. When there were meta-analyses, we have preferred to enter the data of each one of the studies that made up such analysis into the model. We organized 34 comparison pairs in a spreadsheet (Microsoft Excel) found in the 28 selected studies. We used the Odds Ratio (OR) plus the calculation of $\operatorname{lnOR}$ and its Standard Error (SE[lnOR]) to measure the effect size in the network meta-analysis. Data extraction differences were solved by consensus among researchers. We preferred a short-term approach $(<12$ weeks) extracting the data corresponding to subjects on intention to treat (ITT) final analysis.

We performed the network meta-analysis by using Stata software v10 (StataCorp, TX, USA), complementing it with the Comprehensive Meta-analysis v2 software (Biostat Engelwood, NJ, USA). The coherence analysis was done on the R software, using $\operatorname{lnOR}$ and $\mathrm{SE}(\operatorname{lnOR})$ as effect size, following an adequate command structure for this analysis [14]. Similarly, calculations for the cooccurrence index were made with the aid of the EcoSim v7 software.

\section{Results}

Table 1 shows a synthesis of studies included in the meta-analysis. Twenty three trials had two-arm designs 
Table 1. Characteristics of selected studies.

\begin{tabular}{|c|c|c|c|c|c|c|c|c|}
\hline Author & Design & Duration $^{*}$ & Group & Dose & Age & ITT sample & Oesophagitis & $\begin{array}{l}\text { GERD } \\
\text { relief }\end{array}$ \\
\hline (year) & & (week) & & (mg/day) & years & $\mathbf{N}^{\circ}$ & $\mathbf{N}^{\circ}$ & $\mathbf{N}^{\circ}$ \\
\hline Armstrong & Double-blind, randomized, & 4 & Nizatidine & 300 & $47.6(14.1)$ & 109 & 44 & 37 \\
\hline (2001) [15] & Parallel & & Pantoprazole & 40 & $47.1(14.0)$ & 111 & 39 & 67 \\
\hline Bate & Double-blind, randomized, & 4 & Omeprazole & 20 & $47(14)$ & 98 & 43 & 42 \\
\hline (1996) [16] & Parallel & & Placebo & - & $51(14)$ & 111 & 41 & 15 \\
\hline Bate & Double-blind, randomized, & 4 & Omeprazole & 20 & 49 & 112 & 87 & 74 \\
\hline (1997) [17] & Parallel & & Cimetidine & 1600 & 46 & 109 & 83 & 34 \\
\hline Beeley & Double-blind, randomized, & 2 & Alginate/AA & 1560 & 63.6 & 28 & NS & 21 \\
\hline (1972) [18] & Crossed & & Placebo & - & & 28 & NS & 14 \\
\hline Carlsson & Double-blind, randomized, & 4 & Omeprazole & 10 & 48 & 86 & 0 & 58 \\
\hline (1998) [19] & Parallel & & Placebo & - & 46 & 88 & 0 & 44 \\
\hline Chatfield & Double-blind, randomized, & 4 & Alginate/AA & 4000 & $50(2.0)$ & 48 & NS & 40 \\
\hline (1999) [20] & Parallel & & Placebo & - & $50(1.8)$ & 46 & NS & 17 \\
\hline Ciociola & Double-blind, randomized, & 2 & Ranitidine & 75 & 45 & 516 & NS & 272 \\
\hline (2001) [21] & Parallel & & Placebo & - & 45 & 510 & NS & 214 \\
\hline Eriksen & Double-blind, randomized, & $4-10$ & Cimetidine & 1600 & 55 & 24 & 14 & 1 \\
\hline (1988) [22] & Parallel & & Alginate/AA & 1600 & 47 & 21 & 18 & 5 \\
\hline Galmiche & Double-blind, randomized, & 2 & Ranitidine & $75-225$ & $48(0.6)$ & 504 & 186 & 393 \\
\hline (1998) [23] & Parallel & & Placebo & - & $49.9(0.9)$ & 270 & 105 & 170 \\
\hline Galmiche & Double-blind, randomized, & 2 & Cimetidine & $200-600$ & $50.6(0.7)$ & 515 & 201 & 397 \\
\hline (1998) [23] & Parallel & & Placebo & - & $49.9(0.9)$ & 270 & 105 & 170 \\
\hline Gianini & Open, randomized, & 2 & Alginate/AA & $10 \mathrm{ml}$ qid & $>18$ & 87 & NS & 71 \\
\hline (2006) [24] & Parallel & & Magaldrate & $10 \mathrm{ml}$ qid & & 92 & NS & 68 \\
\hline Holtmeier & Double-blind, randomized, & $6 \mathrm{~h}$ & Hydrotalcite & 1000 & $44.9(12.1)$ & 490 & NS & 402 \\
\hline (2007) [25] & Crossed & & Famotidine & 10 & & 490 & NS & 421 \\
\hline & & & Placebo & - & & 490 & NS & 392 \\
\hline Lanza & Double-blind, randomized, & $1 \mathrm{~h}$ & Alginic $\mathrm{Ac} . / \mathrm{Al}(\mathrm{OH})_{3}$ & 1 a 2 tabs & 36.5 & 60 & NS & 40 \\
\hline (1986) [26] & Crossed & & Mg-trisilicate, $\mathrm{Na}$ & $\mathrm{HCO}_{3}$ & & & & \\
\hline & & & Placebo & 1 a 2 tabs & & 60 & NS & 17 \\
\hline Lind & Double-blind, randomized, & 4 & Omeprazole & 10 & $49(13)$ & 199 & NS & 98 \\
\hline (1997) [27] & Parallel & & Placebo & - & $51(13)$ & 105 & NS & 25 \\
\hline Miner & Double-blind, randomized, & 4 & Rabeprazole & 10 & $44.4(1.5)$ & 64 & 0 & 36 \\
\hline (2002) [28] & Parallel & & Placebo & - & $46.1(1.2)$ & 68 & 0 & 22 \\
\hline Pappa $^{* *}$ & Double-blind, randomized, & 2 & Ranitidine & 75 & 47.4 & 482 & NS & 275 \\
\hline (1999) [29] & Parallel & & Placebo & - & 47.3 & 470 & NS & 197 \\
\hline Richter $^{* *}$ & Double-blind, randomized, & 4 & Omeprazole & 10 & 50 & 118 & NS & 32 \\
\hline (2000) [30] & Parallel & & Placebo & - & 49.7 & 123 & NS & 6 \\
\hline Riemann & Double-blind, randomized, & 2 & Cimetidine & 800 & 48.9 & 60 & NS & 22 \\
\hline (1991) [31] & Parallel & & Placebo & - & 47.1 & 65 & NS & 12 \\
\hline Rue Lai & Double-blind, randomized, & 6 & Alginate/AA & 200 & $41.6(14.8)$ & 69 & NS & 20 \\
\hline (2006) [32] & Parallel & & $\mathrm{Mg}_{6} \mathrm{Al}_{2}(\mathrm{OH})_{16} \mathrm{CO}_{3}$ & 500 & $42.4(11.8)$ & 65 & NS & 6 \\
\hline Simon & Double-blind, randomized, & 4 & Famotidine & 10 a 20 & 43.5 & 113 & 62 & 81 \\
\hline (1995) [33] & Parallel & & $\begin{array}{l}\mathrm{Mg} / \mathrm{Al} \text { Hydroxide } \\
(\mathrm{ANC}=11 \mathrm{mEq})\end{array}$ & 1 to 2 tabs & 45.3 & 113 & 67 & 75 \\
\hline \multirow{4}{*}{$\begin{array}{c}\text { Stanciu } \\
(1974)[34]\end{array}$} & \multirow{4}{*}{ Randomized, parallel } & \multirow{4}{*}{2} & Placebo & - & 43.3 & 111 & 62 & 64 \\
\hline & & & Alginate/AA & NS & 42.2 & 20 & 12 & 11 \\
\hline & & & Antacid & NS & 46.9 & 20 & 11 & 5 \\
\hline & & & Placebo & NS & 39.8 & 20 & 13 & 7 \\
\hline
\end{tabular}




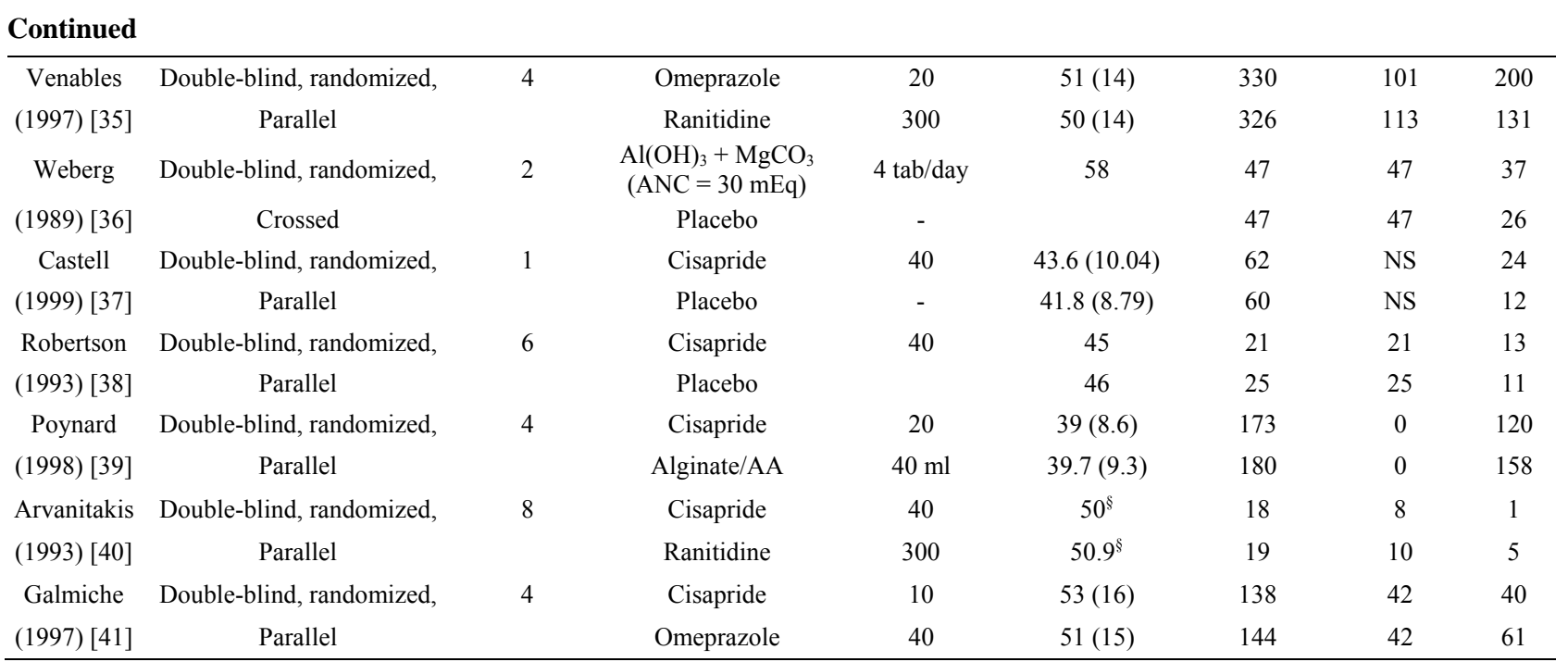

ITT: Intention to treat; NE: Non Specified; NS: Non Specified; "It refers to the observation period with each treatment; ${ }^{* *}$ Number of ITT studies was not specified. Calculations were based upon the number that completed the study; ${ }^{\S}$ : weighted average according to sex.

[15-22,24,26-32,35-41] and four trials were three-arm studies $[23,25,33,34]$. Four trials were excluded from the analysis [42-45] due to the lack of compliance with inclusion criteria and one reference was not considered because it was Data on file (not published) [46]. Figure 1 shows the network of clinical trials according to comparison of specific anti-reflux agent classes. Line thickness refers to the number of studies considered in each comparison.

A comparison network is less diverse when it has a few treatments. Among networks containing the same number of treatments, a network is less diverse when treatments are not equitably represented (since some therapies are used more frequently than others). We use the Probability of Interspecific Encounter (PIE) index, whose value represents the probability that two treatments chosen at random from the network be assigned to two different treatments. The PIE index was 0.81 for our study network. For operational purposes, lower index than 0.75 suggests a limited comparison diversity [47].

Likewise, the co-occurrence index reflects if one or several comparisons of two specific treatments are preferred or avoided. Score-C would reflect the tendency showing that two treatments do not jointly occur. Score$\mathrm{C}$ statistical meaning is measured by using the permutation procedure. P-value lower than 0.05 ( 0.10 for other authors) would suggest the existence of a significant co-occurrence [47]. Score-C was greater than 0.10 for our analysis network.

Figure 2 shows the results of the network meta-analysis taking placebo as reference. According to this data, initial treatments with ALG or PPI are the two interventions that significantly differ from the rest of treatments $\left(\mathrm{H}_{2} \mathrm{RA}, \mathrm{AA}, \mathrm{GK}\right)$; and at the same time, the rest of treatments differ from placebo.

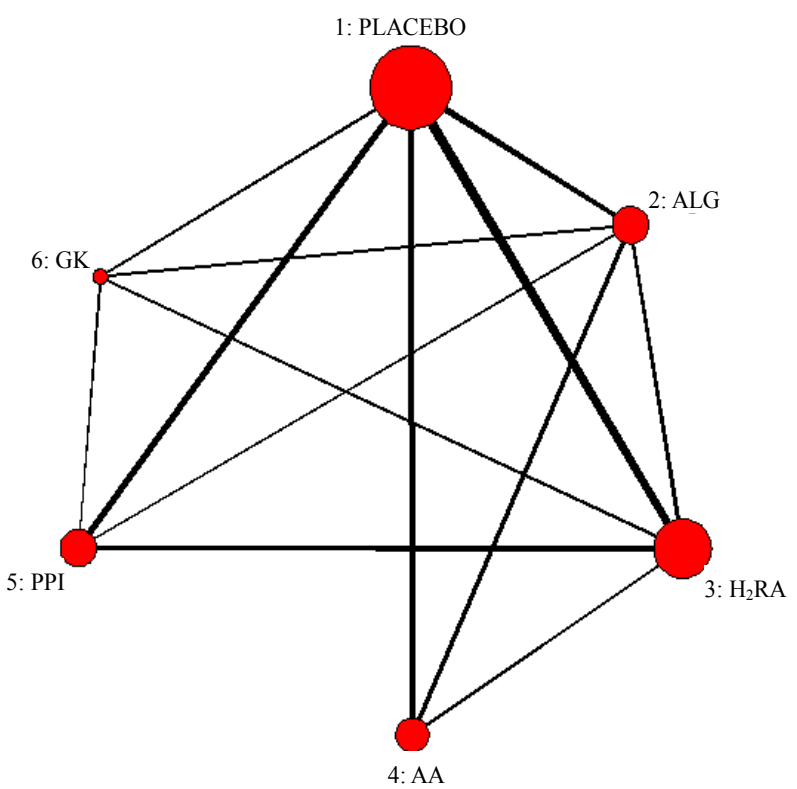

ALG: alginate/antacid; GK: gastrokinetics, PPI: proton pump inhibitors, AA: antacids, $\mathrm{H}_{2} \mathrm{RA}$ : $\mathrm{H}_{2}$ histamine receptor antagonists.

Figure 1. Network of clinical trials comparing efficacy of treatments for GER.

In contrast to placebo, ORs for ALG, PPI, $\mathrm{H}_{2} \mathrm{RA}, \mathrm{AA}$ and GK were 4.72 (95\% CI: 3.39, 6.57), 4.00 (95\% CI: $3.30,4.85), 1.73(95 \%$ CI: $1.54,1.95), 1.41(95 \% \mathrm{CI}$ : $1.12,1.76)$, and 1.86 (95\% CI: 1.32, 2.63), respectively.

Although differences in design and measurement scale of study results show some heterogeneity, the model maintains a non significant incoherence level considering that the analysis of the comparison triangles or "loops" (10 in total) did not reach statistical significance and that confidence intervals included zero. Therefore, statistic estimations and 95\% CI in different "loops" of the study 


\begin{tabular}{lcccr}
\cline { 1 - 4 } Study name & \multicolumn{5}{c}{ Statistics for each study } \\
\cline { 3 - 5 } & $\begin{array}{c}\text { Odds } \\
\text { ratio }\end{array}$ & $\begin{array}{c}\text { Lower } \\
\text { limit }\end{array}$ & $\begin{array}{c}\text { Upper } \\
\text { limit }\end{array}$ & p-Value \\
ALG & 4.718 & 3.390 & 6.567 & 0.000 \\
PPI & 4.002 & 3.303 & 4.849 & 0.000 \\
GK & 1.858 & 1.315 & 2.626 & 0.000 \\
$\mathrm{H}_{2}$ RA & 1.733 & 1.541 & 1.948 & 0.000 \\
AA & 1.405 & 1.120 & 1.764 & 0.003 \\
PLACEBO & 1.000 & 0.999 & 1.001 & 1.000
\end{tabular}

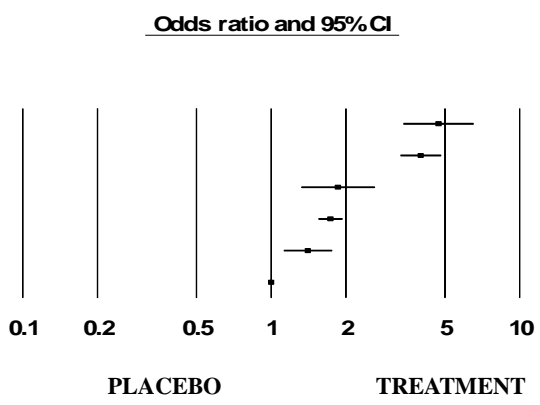

ALG: alginate/antacid, PPI: proton pump inhibitor, GK: gastrokinetic, $\mathrm{H}_{2} \mathrm{RA}$ : $\mathrm{H}_{2}$-histamine receptor antagonist, AA: antacid

Figure 2. Efficacy ranking of anti-reflux treatments as compared to placebo.

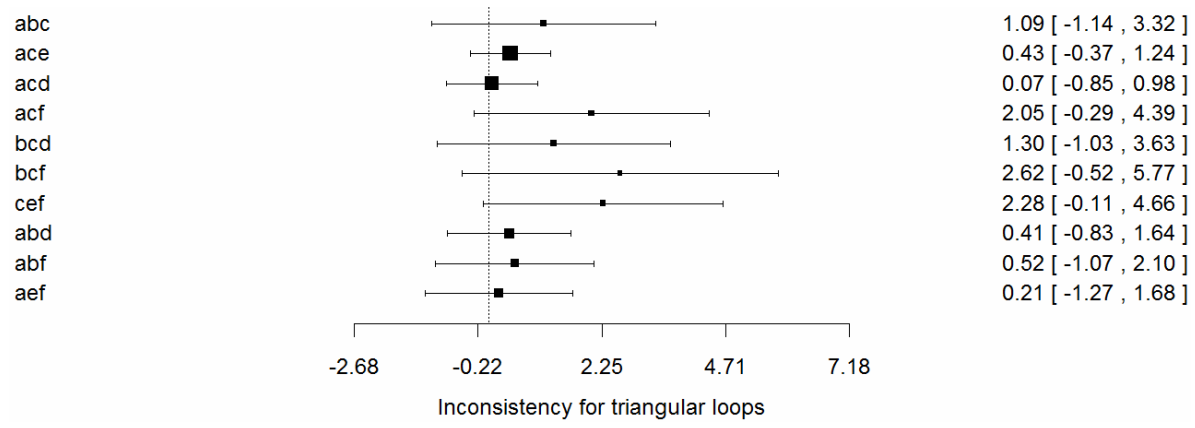

a: PLACEBO; b: ALG; c: $\mathrm{H}_{2} \mathrm{RAs}$; d: AAs; e: PPIs, f: GKs.

Figure 3. Consistency analysis in the triangular loops of comparisons in the study network.

network suggested that the global model is internally consistent and that it might provide a useful estimation of the effect for each individual agent (Figure 3) [14].

\section{Discussion}

The efficacy of three treatment alternatives for GER $\left(\mathrm{H}_{2} \mathrm{RA}, \mathrm{AA}\right.$ and $\left.\mathrm{ALG}\right)$ has been recently evaluated in the Tran et al. meta-analysis [48], analyzing each intervenetion with placebo. Although different treatment strategies with PPI and $\mathrm{H}_{2} \mathrm{RA}$ have been formerly contrasted, we believe that PPIs should be considered as second-line treatment agents because it is important to reserve more effective anti-secretor agents for more defined clinical conditions such as ulcers related to Helicobacter pylori or when there is GER with oesophagitis endoscopic evidence. However, considering that the use of PPIs at low doses has become quite promoted, also boosting OTC formulations, it was important to include this treatment in the analysis. Although PPIs have shown high efficacy in managing GER symptoms, it is necessary to rationalize their use due to adverse reaction reports with long-term therapies such as hypergastrinemia, rebound acid hypersecretion, malabsorption, osteoporosis and infections [1].

Recently, the Cochrane collaboration reviewed evidence on short-term regimes for managing GER, including open studies or comparative studies with PPI, $\mathrm{H}_{2} \mathrm{RA}$ and GK both for pyrosis with or without endoscopic oe- sophagitis [11,12]. Besides endoscopy criteria, evidence was chosen according to the dose and treatment duration, separately evaluating studies with a standard dose ("healing-dose") and maintenance dose (half the standard dose), and they were classified according to treatment duration in $<12$ weeks (short-term) and $\geq 12$ weeks (long-term).

We preferred to use Cochrane data for this analysis in the case of GER with negative endoscopy for oesophagitis and in a short-term perspective [12], together with Tran et al. meta-analysis data, which have synthesized evidence with AA and ALG under a similar time-horizon (4 weeks), an information that complemented quite well that published by Cochrane. Since ALGs have enough evidence, it was important to include such alternative in this meta-analysis and evaluate their efficacy as compared to the other alternatives.

Considering that anti-secretors full doses are not used in many publications we prefer to select comparative arms with the more comparable doses of omeprazole and ranitidine, that is, $10 \mathrm{mg} /$ day and $75-150 \mathrm{mg} / \mathrm{day}$, respectively in those studies where several omeprazole doses have been evaluated. Likewise, some studies evaluated the anti-reflux effect in patients with oesophagitis and without it, in which case we preferred to use the results of the group without oesophagitis, because this is the more frequent condition in the routine practice.

Therefore, this model aims at establishing a compara- 
tive ranking of the efficacy of different agents used in short-term management of GER, taking placebo as reference (Figure 2). In our analysis it is important to highlight the role ALGs would have in single or combined GER treatment, because this alternative has not been sufficiently considered in some formerly published metaanalyses.

Consistency test allows to assuming that there is no important incoherence in the study network in which case the model analysis would not be appropriate (Figure 3). Likewise, data evaluation was done by considering the population per Intention to Treat (ITT) in each trial's arms, which would make the analysis more robust.

Although it is frequently argued that indirect comparisons are only necessary when there are no direct comparisons, it is important to understand that both types of comparisons contribute to total evidence. No matter if direct comparisons enjoy the benefits of randomization; there is no guarantee that these comparisons are less exposed to bias than indirect comparisons are. Actually, you can accept that the bias of a direct comparison may be eliminated by adding an indirect comparison of the same interventions. Such is the main advantage of the network analysis [49].

Sponsors of new therapies launched into the pharmaceutical market make an effort in showing through direct comparisons that they are a better alternative than existing therapies. These demonstrations can sometimes be misled by different kinds of bias, such as publication, reporting or interpreting bias; or through the manipulation of some outcomes as secondary objectives or the subjective analysis of intermediate variables, or else the manipulation of dosing schemes. Nevertheless, a better bias analysis bias analysis can be achieved when evaluating evidence by means of the network meta-analysis, that is, by combining direct and indirect comparisons and exploring possible model inconsistency sources.

Finally, it is important to observe some weaknesses in the model. First, although the teme-horizon of our study was defined for the short-term $(<12$ weeks), long-term data may increase efficacy differences between treatments according to this last factor, PPIs might show greater benefits in the long-term, but this conclusion needs to be counterbalanced with their adverse effect potential. Second, in spite of the fact that the internal coherence analysis of trials does not suggest much inconsistency of the model, we should consider that clinical improvement is not reported under the same measureing scale and that there is no standardized dose of different treatment regimes either (for example, ALG/AA formulations do not have the same composition through different trials), and that might generate an important heterogeneity level that would reduce outcome robustness.

\section{Conclusion}

In spite of the fact that considered treatments showed they were significantly more effective than placebo, interventions with ALG or PPI seem to be the most effective alternative in short-term management $(<12$ weeks $)$ for GER with or without oesophagitis.

\section{Acknowledgements}

We thank Paola Laverde for her valuable and professional support in the systematic review.

\section{REFERENCES}

[1] T. Oscanoa, "Seguridad de los Inhibidores de la Bomba de Protones," Revista de Gastroenterología del Perú, Vol. 31, No. 1, 2011, pp. 49-55.

[2] D. Gillen, A. A. Wirz, J. E. Ardill, et al., "Rebound Hypersecretion after Omeprazole and Its Relation to OnTreatment Acid Suppression and Helicobacter pylori Status," Gastroenterology, Vol. 116, No. 2, 1999, pp. 239-247. doi:10.1016/S0016-5085(99)70118-6

[3] M. Broeren, E. Geerdink, H. Vader and A. Warmold, "Hypomagnesemia Induced by Several Proton-Pump Inhibitors," Annals of Internal Medicine, Vol. 151, 2009, pp. 755-756.

[4] "El uso Prolongado y Regular de Inhibidores de la Bomba de Protones (PPI) Puede Reducir el Nivel de Magnesio," Boletín Farmacos, Vol. 14, No. 2, 2011, pp. http://www.saludyfarmacos.org/boletin-farmacos/

[5] C. Kapadia and V. Mane, "Raft-Forming Agents: AntiReflux Formulations," Drug Development and Industrial Pharmacy, Vol. 33, No. 12, 2007, pp. 1350-1361. doi:10.1080/03639040701385691

[6] K. G. Mandel, B. P. Daggy, D. A. Brodie and H. I. Jacoby, "Review Article: Alginate-Raft Formulations in the Treatment of Heartburn and Acid Reflux," Alimentary Pharmacology \& Therapeutics, Vol. 14, No. 6, 2000, pp. 669-690. doi:10.1046/j.1365-2036.2000.00759.x

[7] N. Vakil, T. Rydén-Bergsten and K. Bergenheim, "Systematic Review: Patient-Centred Endpoints in Economic Evaluations of Gastro-Oesophageal Reflux Disease," Alimentary Pharmacology \& Therapeutics, Vol. 16, No. 8, 2002, pp. 1469-1480. doi:10.1046/j.1365-2036.2002.01303.x

[8] I. Mason and N. J. Marchant, "Management of AcidRelated Dispepsia in General Practice," Clinical Drug Investigation, Vol. 18, No. 2, 1999, pp. 117-124. doi:10.2165/00044011-199918020-00004

[9] A. Briggs, R. Goeree, G. Blackhouse and B. O'Brien, "Probabilistic Analysis of Cost-Effectiveness Models: Choosing between Treatment Strategies for Gastroesophageal Reflux Disease," Medical Decision Making, Vol. 22, 2002, pp. 290-308.

[10] C. Donnellan, C. Preston, P. Moayyedi and N. Sharma, "Medical Treatments for the Maintenance Therapy of Reflux Oesophagitis and Endoscopic Negative Reflux Dis- 
ease," Cochrane Database of Systematic Reviews. The Cochrane Library, No. 6, 2009, Article ID: CD003245. doi:10.1002/14651858.CD003245.pub2

[11] P. Moayyedi, J. Santana, M. Khan, C. Preston and C. Donnellan, "Medical Treatments in the Short Term Management of Reflux Oesophagitis," Cochrane Database of Systematic Reviews. The Cochrane Library, No. 6, 2009, Article ID: CD003244. doi:10.1002/14651858.CD003244.pub2

[12] B. van Pinxteren, K. E. Sigterman, P. Bonis, J. Lau and M. E. Numans, "Short-Term Treatment with Proton Pump Inhibitors, H2-Receptor Antagonists and Prokinetics for Gastro-Oesophageal Reflux Disease-Like Symptoms and Endoscopy Negative Reflux Disease," Cochrane Database of Systematic Reviews. The Cochrane Library, No. 6, 2006, Article ID: CD002095. doi:10.1002/14651858.CD002095.pub2

[13] A. Jadad, D. Moher, G. Nichol, M. Penman, P. Tugwell and S. Walsh, "Assessing the Quality of Randomized Controlled Trials: An Annotated Bibliography of Scales and Checklists," Controlled Clinical Trials, Vol. 16, No. 1, 1995, pp. 62-73. doi:10.1016/0197-2456(94)00031-W

[14] Multiple Treatments Meta-Analysis, "A Framework for Evaluating and Ranking Multiple Healthcare Technologies." http://www.mtm.uoi.gr/

[15] D. Armstrong, P. Paré, D. Pericak, M. Pyzyk and The Canadian Pantoprazole GER Study Group, "Symptom Relief in Gastroesophageal Reflux Disease: A Randomized, Controlled Comparison of Pantoprazol and Nizatidine in a Mixed Patient Population with Erosive Esophagitis or Endoscopy-Negative Reflux Disease," The American Journal of Gastroenterology, Vol. 96, 2001, pp. 2849-2857.

[16] C. M. Bate, S. M. Griffin, P. W. Keeling, A. T. Axon, M. W. Dronfield, et al., "Reflux Symptom Relief with Omeprazole in Patients without Unequivocal Oesophagitis," Alimentary Pharmacology \& Therapeutics, Vol. 10, No. 4, 1996, pp. 547-555. doi:10.1046/j.1365-2036.1996.44186000.x

[17] C. M. Bate, J. R. Green, A. T. Axon, F. E. Murray, G. Tildesley, et al., "Omeprazol Is More Effective than Cimetidine for the Relief of All Grades of Gastro-Oesophageal Reflux Disease-Associated Heartburn, Irrespective of the Presence or Absence of Endoscopic Oesophagitis," Alimentary Pharmacology \& Therapeutics, Vol. 11,No. 4, 1997, pp. 755-763. doi:10.1046/j.1365-2036.1997.00198.x

[18] M. Beeley and J. Warner, "Medical Treatment of Symptomatic Hiatus Hernia with Low-Density Compounds," Current Medical Research and Opinion, Vol. 1, No. 2, 1972, pp. 63-69. doi:10.1185/03007997209111146

[19] R. Carlsson, J. Dent, R. Watts, S. Riley, R. Sheikh, et al., "Gastro-Oesophageal Reflux Disease in Primary Care: An International Study of Different Treatment Strategies with Omeprazole," European Journal of Gastroenterology \& Hepatology, Vol. 10, No. 2, 1998, pp. 119-124. doi:10.1097/00042737-199802000-00004

[20] S. Chatfield, "A Comparison of the Efficacy of the Alginate Preparation, Gaviscon Advance, with Placebo in the
Treatment of Gastro-Oesophageal Reflux Disease," Current Medical Research and Opinion, Vol. 15, No. 3, 1999, pp. 152-159. doi:10.1185/03007999909114086

[21] A. Ciociola, K. Pappa and M. Sirgo, "Nonprescription Doses of Ranitidine Are Effective in the Relief of Episodic Heartburn," American Journal of Therapeutics, Vol. 8, No. 6, 2001, pp. 399-408. doi:10.1097/00045391-200111000-00004

[22] C. A. Eriksen, W. G. Cheadle, C. A. Cranford and A. Cuschieri, "Combined Cimetidine-Alginate Antacid Therapy versus Single Agent Treatment for Reflux Oesophagitis," Annales Chirugiae et Gynaecologiae, Vol. 77, 1988, pp. 133-137.

[23] J. P. Galmiche, G. Shi, B. Simon, F. Casset-Semanasanaz and A. Slama, "On-Demand Treatment of Gastro-Oesophageal Reflux Symptoms: A Comparison of Ranitidine $75 \mathrm{mg}$ with Cimetidine $200 \mathrm{mg}$ or Placebo," Alimentary Pharmacology \& Therapeutics, Vol. 12, No. 9, 1998, pp. 909-917. doi:10.1046/j.1365-2036.1998.00384.x

[24] E. Giannini, P. Zentilin, P. Dulbecco, R. Iritano, C. Bilardi, et al., "A Comparison between Sodium Alginate and Magaldrate Anhydrous in the Treatment of Patients with Gastroesophageal Reflux Symptoms," Digestive Diseases and Sciences, Vol. 51, No. 11, 2006, pp. 1904 1909. doi:10.1007/s10620-006-9284-0

[25] W. Holtmeier, G. Holtmann, W. Caspary and U. Weingärtner, "On-Demand Treatment of Acute Heartburn with the Antacid Hydrotalcite Compared with Famotidine and Placebo," Journal of Clinical Gastroenterology, Vol. 41, No. 6, 2007, pp. 564-570. doi:10.1097/MCG.0b013e31802e7efb

[26] F. L. Lanza, V. Smith, J. A. Page-Castell and D. O. Castell, "Effectiveness of Foaming Antacid in Relieving Induced Heartburn," Southern Medical Journal, Vol. 79, No. 3, 1986, pp. 327-330. doi:10.1097/00007611-198603000-00017

[27] T. Lind, T. Havelund, R. Carlsson, O. Anker-Hansen and H. Glise, "Heartburn without Oesophagitis: Efficacy of Omeprazole Therapy and Features Determining Therapeutic Response," Scandinavian Journal of Gastroenterology, Vol. 32, No. 10, 1997, pp. 974-979. doi: $10.3109 / 00365529709011212$

[28] P. Miner, W. Orr, J. Filippone, L. Jokubaitis and S. Sloan, "Rabeprazole in Norerosive Gastroesophageal Reflux Disease: A Randomized Placebo-Controlled Trial," The American Journal of Gastroenterology, Vol. 97, 2002, pp. 1332-1339. doi:10.1111/j.1572-0241.2002.05769.x

[29] K. A. Pappa, W. M. Gooch, K. Buaron, J. E. Payne, E. E. Giefer, et al., "Low-Dose Ranitidine Fir the Relief of Heartburn," Alimentary Pharmacology \& Therapeutics, Vol. 13, No. 4, 1999, pp. 459-465. doi:10.1046/j.1365-2036.1999.00507.x

[30] J. Richter, D. Peura, S. Benjamin, B. Joelsson and J. Whipple, "Efficacy of Omeprazole for the Treatment of Symptomatic Acid Reflux Disease without Esophagitis," Archives of Internal Medicine, Vol. 160, No. 12, 2000, pp. 1810-1816. doi:10.1001/archinte.160.12.1810

[31] J. F. Riemann and W. Höbel, "Cimetidine Suspension in Patients with Stage 0 Gastro-Oesophageal Reflux Dis- 
ease," Alimentary Pharmacology \& Therapeutics, Vol. 5, No. 2, 1991, pp. 191-197. doi:10.1111/j.1365-2036.1991.tb00020.x

[32] I.-R. Lai, M.-S. Wu and J.-T. Lin, "Prospective, Randomized, and Active Controlled Study of the Efficacy of Alginic Acid and Antacid in the Treatment of Patients with Endoscopy-Negative Reflux Disease," World Journal of Gastroenterology, Vol. 12, 2006, pp. 747-754.

[33] T. Simon, R. Berlin, A. Gardner, L. Stauffer, A. Lawrence, et al., "Self-Directed Treatment of Intermittent Heartburn: A Randomized, Multicenter, Double-Blind, Placebo-Controlled Evaluation of Antacid and Low Doses of an H2-Receptor Antagonist (Famotidine)," World Journal of Gastroenterology, Vol. 2, No. 5, 1995, pp. 304-313. doi:10.1097/00045391-199505000-00003

[34] C. Stanciu and J. Bennett, "Alginate/Antacid in the Reduction of Gastro-Oesophageal Reflux," Lancet, Vol. 303, No. 7848, 1974, pp. 109-111. doi:10.1016/S0140-6736(74)92340-X

[35] T. L. Venables, R. D. Newland, A. C. Patel, J. Hole, C. Wilcock, et al., "Omeprazole 10 Milligrams Once Daily, Omeprazole 20 Milligrams Once Daily, or Ranitidine 150 Milligrams Twice Daily, Evaluated as Initial Therapy for the Relief of Symptoms of Gastro-Oesophageal Reflux Disease in General Practice," Scandinavian Journal of Gastroenterology, Vol. 32, No. 10, 1997, pp. 965-973. doi:10.3109/00365529709011211

[36] R. Weberg and A. Berstad, "Symptomatic Effect of a Low-Dose Antacid Regimen in Reflux Oesophagitis," Scandinavian Journal of Gastroenterology, Vol. 24, No. 4, 1989, pp. 401-406. doi:10.3109/00365528909093066

[37] D. Castell, D. Silvers, T. Littlejohn, W. Orr, J. Napolitano, et al., "Cisapride $20 \mathrm{mg}$ b.d. for Preventing Symptoms of GER Induced by a Provocative Meal," Alimentary Pharmacology \& Therapeutics, Vol. 13, No. 6, 1999, pp. 787794. doi:10.1046/j.1365-2036.1999.00525.x

[38] C. S. Robertson, D. F. Evans, S. J. Ledingham and M. Atkinson, "Cisapride in the Treatment of Gastro-Oesophageal Reflux Disease," Alimentary Pharmacology \& Therapeutics, Vol. 7, No. 2, 1993, pp. 181-190. doi:10.1111/j.1365-2036.1993.tb00088.x

[39] T. Poynard, B. Vernisse and H. Agostini, "Randomized, Multicenntre Comparison of Sodium Alginate and Cisapride in the Symptomatic Treatment of Uncomplicated Gastrooesophageal Reflux," Alimentary Pharmacology \& Therapeutics, Vol. 12, No. 2, 1998, pp. 159-165. doi:10.1046/j.1365-2036.1998.00283.x

[40] C. Arvanitakis, A. Nikopoulus, A. Theoharidis, E. Gianooulis, I. Vagios, et al., "Cisapride and Ranitidine in the Treatment of Gastro-Oesophageal Reflux Disease-A Comparative Randomized Double-Blind Trial," Alimentary Pharmacology \& Therapeutics, Vol. 7, No. 6, 1993, pp. 635-641. doi:10.1111/j.1365-2036.1993.tb00145.x

[41] J. P. Galmiche, P. Barthelemy and B. Hamelin, "Treating the Symptoms of Gastro-Oesophageal Reflux Disease: A Double-Blind Comparison of Omeprazole and Cisapride," Alimentary Pharmacology \& Therapeutics, Vol. 11, No. 4, 1997, pp. 765-773.

doi:10.1046/j.1365-2036.1997.00185.x

[42] P. W. Dettmar, J. Sykes, S. L. Little and J. Bryan, "Rapid Onset of Effect of Sodium Alginate on Gastro-Oesophageal Reflux Compared with Ranitidine and Omeprazole, and Relationship between Symptoms and Reflux Episodes," International Journal of Clinical Practice, Vol. 60, No. 3, 2006, pp. 275-283.

doi:10.1111/j.1368-5031.2006.00800.x

[43] N. Washington, R. J. Steele, S. J. Jackson, C. Washington and D. Bush, "Patterns of Food and Acid Reflux in Patients with Low-Grade Oesophagitis: The Role of an Anti-Reflux Agent," Alimentary Pharmacology \& Therapeutics, Vol. 12, No. 1, 1998, pp. 53-58. doi:10.1046/j.1365-2036.1998.00277.x

[44] N. Washington, J. L. Greaves and S. Y. Iftikhar, “A Comparison of Gastro-Oesophageal Reflux in Volunteers Assessed by Ambulatory $\mathrm{pH}$ and Gamma Monitoring after Treatment with Either Liquid Gaviscon or Algicon Suspension," Alimentary Pharmacology \& Therapeutics, Vol. 6, No. 5,1992 , pp. 579-588. doi:10.1111/j.1365-2036.1992.tb00572.x

[45] D. G. Maxton, J. P. Miller, P. J. Whorwell and J. K. Butler, "A Study of Algicon, an Antacid-Alginate Preparation, in Patients with Reflux Oesophagitis," The British Journal of Clinical Practice, Vol. 42, 1988, pp. 368-371.

[46] S. H. Korn, A. Murakami, L. A. Stauffer and R. W. Tipping, "A Controlled Comparison of Symptom Relief Provided by a Famotidine/Antacid Combination Tablet for the Treatment of Frequent Heartburn," Data on File of Merck Research Laboratories.

[47] G. Salanti, F. Kavvoura and J. Loannidis, "Exploring the Geometry of Treatment Networks," Exploring the Geometry of Treatment Networks, Vol. 148, 2008, pp. 544 553.

[48] T. Tran, A. M. Lowry and H. B. El-Serag, "Meta-Analysis: The Efficacy of Over-the-Counter Gastro-Oesophageal Reflux Disease Therapies," Alimentary Pharmacology \& Therapeutics, Vol. 25, 2006, pp. 143-153.

[49] J. P. Jansen, R. Fleurence, B. Devine, R. Itzler, A. Barrett, et al., "Interpreting Indirect Treatment Comparisons and Network Meta-Analysis for Health-Care Decision Making: Report of the ISPOR Task Force on Indirect Treatment Comparisons Good Research Practices: Part 1," Value in Health, Vol. 14, No. 4, 2011, pp. 417-428. doi:10.1016/j.jval.2011.04.002 